\title{
Servitización y creación de valor: Implementación en plataformas de dispositivos móviles
}

La Servitización está siendo en la actualidad objeto de análisis por parte de la literatura especializada en la medida en que trata la incorporación de servicios en empresas manufactureras con el fin de crear valor. Aunque tradicionalmente las empresas siempre han ofrecido servicios vinculados a sus productos, especialmente garantías y mantenimiento, las nuevas tendencias asociadas al proceso de servitización ha dotado a estos servicios de una significación mucho mayor como generadores de valor añadido para el cliente. Es en este contexto, en el que las nuevas tecnologías de la información tienen un papel crucial en el proceso de servitización, especialmente en el ámbito de los dispositivos móviles a través de los cuales se puede producir una comunicación directa entre la empresa y los usuarios. En este trabajo, proponemos la implementación de la servitización como motor de creación de valor a través de las nuevas oportunidades tecnológicas que generan las plataformas de dispositivos móviles, tanto abiertas como cerradas en un contexto que va desde los desarrolladores hasta los usuarios finales.

De este modo, las empresas hacen cada vez más esfuerzos en conocer los gustos, tendencias, necesidades y deseos de sus clientes a la hora de desarrollar nuevos productos y servicios. Para ello, tratan de recopilar grandes cantidades de información tanto a través de medios tradicionales como del uso de las tecnologías de la información. A este respecto, los dispositivos móviles constituyen un elemento fundamental a través de los cuales los usuarios pueden comunicar multitud de datos que permitan a la empresa configurar su estrategia de posicionamiento en el mercado a la vez que desarrollar acciones de servitización. Así, las plataformas cerradas permiten a los desarrolladores elaborar aplicaciones que, una vez instaladas, pueden crear vías de comunicación de información de datos muchas veces fomentadas a través de la gamificación o uso de las técnicas de videojuegos para motivar al usuario conocer más sobre los productos y servicios de la empresa y a informar a la misma sobre sus preferencias. Las plataformas abiertas dan un paso más y permiten no sólo el uso de estas aplicaciones, sino la creación de ROMs específicas sobre la base de este tipo de plataformas. Esto permite un nivel aún mayor de intercomunicación y servitización sobre el dispositivo móvil de usuario. Casos como la alianza entre Nike y Apple para incluir una aplicación nativa en IPod para corredores, que mide recorridos, calorías, tiempo, etc. a través de un chip en determinadas zapatillas deportivas de la marca o el reciente acuerdo entre Google y Nestlé para denominar Kit Kat a la última versión de Android, ilustran esta tendencia.

Actualmente, las empresas se encuentran ante diferentes plataformas siendo Android de Google, IOS de Apple y Windows Phone de Microsoft, las principales en número de usuarios. La presión y el empuje tecnológico unido a la optimización de la estructura de costes han favorecido el desarrollo de estas plataformas tecnológicas base que están convirtiéndose en sistemas dinámicos de interacción entre el cliente y la empresa, convirtiéndose a la vez en un aspecto fundamental en los modelos de negocio actuales. Las plataformas se han convertido en un instrumento vehicular entre Internet y los operadores móviles. La supervivencia de las plataformas y de las aplicaciones se fundamenta en los desarrolladores, los servicios que prestan y los proveedores de contenidos. No obstante, son las propias plataformas las que marcan la evolución del mercado por delante del propio hardware. Esto facilita la incorporación de dichas plataformas en dispositivos que van más allá de los convencionales (Smartphones y Tablets) para ser incorporados en electrodomésticos, relojes de pulsera, dispositivos del automóvil, etc. Esto genera una enorme oportunidad de servitización para las empresas de productos y servicios que encajen no sólo en la configuración de este nuevo tipo de dispositivos, sino también en como canales de comunicación y venta adicionales de servicios asociados al producto. Finalmente, es necesario destacar que no es probable que una sola plataforma abierta o cerrada monopolice el mercado. Por el contrario, las tendencias indican una segmentación de usuarios "premium" hacia $i O S$ frente a usuarios "comunes" hacia Android, quedando el resto de plataformas para opciones de carácter más minoritario aunque con grandes expectativas de crecimiento futuras.

Así, a modo de conclusión, las oportunidades de creación de valor a través de la servitización sobre plataformas de dispositivos móviles son infinitas. Aquellas empresas que logren vincular con éxito el proceso de servitización con el uso intensivo de estas plataformas configurarán los nuevos mercados tecnológicos. 